Article

\title{
\#MeToo? Legal Discourse and Everyday Responses to Sexual Violence
}

\author{
Alison Gash and Ryan Harding * \\ Department of Political Science, University of Oregon, Eugene, OR 97403, USA; gash@uoregon.edu \\ * Correspondence: rharding@uoregon.edu
}

Received: 25 February 2018; Accepted: 16 May 2018; Published: 21 May 2018

\begin{abstract}
Legal consciousness scholars identify the ways in which law is referenced to authorize, define and evaluate behaviors and choices that occur far outside any formal legal framework. They define legality as the "meanings, sources of authority, and cultural practices that are commonly recognized as legal, regardless of who employs them or for what ends." We use the idea of legality to argue that, in matters of sexual assault and rape, the limits of the law extend beyond the courtroom. Rather than simply influencing or guiding only those who are willing to consult the law in their efforts to seek justice, laws and legal discourse have the potential to frame and constrain any attempt to discuss experiences of sexual violence. \#MeToo and other forms of "consciousness-raising" for sexual violence highlight the limiting effects of law and legal discourse on public discussion of sexual violence. We find that, paradoxically, in the case of sexual violence law has the capacity to undermine the goals and benefits of consciousness-raising approaches, privatizing the experience of sexual assault and silencing its victims.
\end{abstract}

Keywords: legality; rape; sexual assault; sexual violence; \#MeToo; law; legal consciousness; consciousness-raising

\section{Introduction}

In 2006, Tarana Burke launched Me Too-a non-profit that focused on providing space for women who have traditionally been isolated from public debates about rape and sexual assault to talk about their experiences. It is about "empowerment through empathy," explained Burke in a recent interview with Ebony magazine. "It was a catchphrase to be used from survivor to survivor to let folks know that they were not alone and that a movement for radical healing was happening and possible" (Hill 2017).

Twelve years later, \#MeToo was adopted as a call to arms to all victims of sexual assault in the midst of the public and volatile campaign to remove Harvey Weinstein-media mogul and accused serial sexual predator-from his post as Hollywood's kingmaker. Weinstein had initially been exposed by reporters at the New York Times and the New Yorker as having committed decades of sexual transgressions against actresses-including many who had risen to fame. Although Weinstein's predatory practices were no secret (journalists and actresses had tried to publicize Weinstein's sexual predation on prior occasions, to no avail), this time the response was swift. Four male members of Weinstein's board of directors resigned within $24 \mathrm{~h}$ of the allegations being publicized. Weinstein's removal by his remaining board members shortly followed suit. Emboldened by this new outrage towards sexual assault and harassment, numerous actors and actresses came forward to disclose their own experiences with other Hollywood royalty, toppling several A-list actors, and quickly spreading to other arenas. Kevin Spacey lost his standing as one of Hollywood's elite after allegations of multiple instances of sexual assault emerged on Twitter. Jeffrey Tambor resigned from his leading role on the Amazon hit Transparent, following multiple allegations of sexual harassment. A Ninth Circuit judge stepped down from his long tenure on the appellate court amidst similar claims, as did Wayne Pacelle, 
the head of the Humane Society. Several members of the House and Senate, including, most notably, Senator Al Franken-a ranking member of the Senate Judiciary Committee and avowed supporter for women's rights-left public office or announced their retirement shortly after allegations of sexual harassment had surfaced on social media.

In the midst of what seemed to be a nationwide awakening to the prevalence of sexual harassment and assault, actress and activist Alyssa Milano took to Twitter to fan the growing flames of outrage. Familiar with-and cognizant of - the power of Burke's Me Too approach-Milano asked her followers to retweet \#MeToo if they had also been the victims of sexual assault or harassment. The purpose was to demonstrate the magnitude of the problem of sexual degradation. Within days, Twitter and dozens of other public forums were awash in \#MeToo postings—and sexual assault hotlines experienced a massive surge in callers seeking help and support. ${ }^{1}$

The ousting of Harvey Weinstein, and the \#MeToo movement that followed, reveal the importance of social media and other public media outlets as potential and powerful venues for individuals to process their experiences with sexual violence. Where discussions of specific instances of sexual violence have been, for the most part, limited to private or intimate conversations-or, in rare moments, during courtroom testimony-newspapers, Twitter, blogs and other social media outlets are now eager to publish personal stories about these experiences. In 2018, with a sitting President facing multiple allegations of sexual assault and harassment and a women-led resistance movement ready to act on any semblance of sexual violation, Weinstein and his ilk had met their match.

However, \#MeToo and its offshoots also reveal the challenges that victims and survivors of sexual violence and degradation continue to confront in their attempts to articulate their experiences. Legal options remain largely inviable for most victims of sexual assault—and only marginally helpful for victims of sexual harassment. Few victims report instances of sexual assault or prevail in court (Du Mont et al. 2003; Estrich 1987). Constitutional commitments to due process, which require any method of legal adjudication to follow defined protocols and satisfy specific evidentiary burdens, make it difficult for claims of sexual assault to prevail. Additionally, these crimes occur primarily in private settings and without any witnesses beyond perpetrator and victim, hinging any verdict almost exclusively on physical evidence and perpetrator/victim credibility. For this reason, many victims of sexual violence forego any attempt to seek legal redress for these violations.

However, we argue, in matters of sexual assault and rape, law's influence extends far beyond the courtroom. Rather than simply shaping how sexual violence survivors narrate their experiences during interactions with legal actors or within legal venues, laws and legal discourse have the potential to determine how sexual violence is articulated, considered, or discussed in a range of settings, even when survivors have not sought legal redress. Specifically, we argue that \#MeToo and other forms of "consciousness-raising" for sexual violence highlight how law and legal discourse can limit and constrain public discussion of sexual violence. Paradoxically, in some circumstances, the force of law in the case of sexual violence is to undermine the goals and benefits of consciousness-raising approaches, resulting in the continued silencing of sexual violence and its victims.

\section{Law and Legal Discourse in the Everyday}

Much of American public life is adjudicated and resolved through litigation or consultation of laws and regulations. Laws supply logics that help to regulate our relationships, our interactions, how we behave, what we say and how we live. Even if there is little likelihood of having any explicit formal legal interaction, legal frameworks offer de facto constraints on numerous aspects of our everyday lives. However, despite the "everyday" relevance of law and legal discourse, so much of the study of law is confined to those instances when we rely upon or utilize formal legal doctrines and

1 The sexual assault hotline managed by RAINN (Rape and Incest National Network) increased by 25 percent in November from one year prior and by 30 percent in December from the same time the previous year (Lambert 2018). 
settings. When we limit the study of law to these doctrines and institutions we miss an opportunity to identify how law both constructs and is constructed by its everyday context (Engel 1995; Ewick and Silbey 1998; Gash and Raiskin 2016). Whether it is "the law of the check-out line" (Engel 1995, p. 125), how we navigate traffic, or the ways we work through disagreements or debates with colleagues, family or friends, our most routine behaviors and transactions are, in part, governed by approximations or interpretations of legal concepts, norms and procedures.

Scholars have developed a framework for understanding how "our social roles and statuses, our relationships, our obligations, prerogatives, and responsibilities, our identities, and our behaviors bear the imprint of the law" (Ewick and Silbey 1998). They use the term "legal consciousness" to identify the ways in which law is referenced to authorize, define and evaluate behaviors and choices that occur far outside any formal legal framework, and define this inclination to turn to the language and lens of law when engaging in "everyday" activities as "legality." Legality refers to the "meanings, sources of authority, and cultural practices that are commonly recognized as legal, regardless of who employs them or for what ends" (Ewick and Silbey 1998, p. 22). Legality suggests that, whether enacted through norms, standards, or routines, the effect of law is pervasive.

Law helps to organize our lives, guide our decision-making strategies, understand our options, identify our power and respond to and evaluate events in the world around us. Of course, individuals do not engage formal legal structures or invoke explicit legal doctrine each time they manage conflicts or complications. Instead, as legal consciousness scholars argue, individuals rely on legality, which "operates through social life as persons and groups deliberately interpret and invoke law's language, authority and procedures to organize their lives and manage their relationships" (Ewick and Silbey 1998, p. 20). Within the concept of legality emerges a new view of the law and the operation of legal discourse. The law is not just an instance or aggregation of formal rules and decisions. It is a "rule of thumb" or heuristic frequently used by each of us to determine what is possible, acceptable, authorized or prohibited. Indeed, the value of the rule of law, as understood through the concept of legality, exists in its ability to self-enforce. Most individuals do not require judges or officers of the law to monitor or advise their every move. Rather, legality can serve as an effective restraint on our predilections for chaos or unruliness-defining what is fair, just, or decent-and as a lens through which everyday experiences are filtered. Through legality, the law is transformed from a codified corpus of rules and procedures into a self-enforcing regulative ideal, putting down parameters that frame the everyday interactions and decisions of ordinary people.

The concept of legality, however, provides more than just a framework for understanding how individuals use the law to manage their own lives. It also offers an account of how they self-deputize, becoming "legal agents [who] make law, even when no formal legal agent is involved" (Ewick and Silbey 1998, p. 20). The implications of both the presence of law in everyday interactions and the capacity for individuals to authorize themselves as trustees of the law are especially critical for understanding the role of legal discourse in shaping extra-legal discussions of sexual violence.

For one, scholars highlight the ways in which law and legality have an especially limiting effect on the lives of women. Formal law, argues Catherine Mackinnon, is inadequate, irrelevant or antagonistic to the everyday lives of women. "Either the law does not apply," MacKinnon explains, "is applied to women's lives to their detriment or is not applied at all" (MacKinnon 2005, p. 34). Even if women choose not to engage in or invoke formal legal institutions and protections, legality can facilitate the downgrading of women's experiences, for example, during conversations or interactions with medical professionals, social-service agencies, or human-resource managers. In the context of sexual violence, rape law can constrain options for adjudication and healing within, and beyond, formal legal institutions. As MacKinnon argues, for women "to the extent that your reality does not fit the law's picture, your rape is not illegal" (MacKinnon 1995, p. 113). Even when-as is true in the vast majority of cases-victims of sexual violence avoid making claims in formal legal venues, their discussions and feelings of sexual violation are often evaluated through the lens and with the imprimatur of the law. 
We argue that, through legality, law has significant presence and power in the discourse on sexual violence. Law can encroach upon and constrain the promise of consciousness-raising by limiting the use of concepts such as "rape" and "sexual assault" to formal legal, evidence-based standards. Through legal discourse, those who use terms such as "sexual assault" as a way of making sense of or naming their violence may be subjected to ongoing versions of law-bound, yet unregulated, interrogations. Therefore, law may not only foreclose on the possibility of survivors of sexual violence seeking and receiving justice within formal legal settings, but may similarly dampen their ability to seek out or receive support, acceptance and healing through consciousness-raising discourse.

\section{Law's Limits in the Courts}

Feminist legal reformers saw great potential for the law to provide an answer to the ongoing problem of sexual violence. Law could provide women with a framework to both describe their violent and dehumanizing experiences and seek justice for these crimes. By promoting the rule of law as the answer to sexual violence, feminist legal reformers were rendering rape and sexual assault a public problem. No longer was sexual violence a private matter that women were required to endure on their own or in the private spheres that other women inhabited. Instead, feminists argued that rape, similar to any other crime, was an assault on the values of a just society, and required a publicly-supported and legally-sanctioned punishment. For the most part, these attempts were successful. Reforms eventually made their way to every state in the nation, and in many ways legal reforms continue to change how we think about rape and sexual assault. There are, however, limits to these efforts-some of which stem from formal legal institutional constraints and others that emanate from gendered conceptions of bodily autonomy that have become entwined within the fabric of American law.

\subsection{Reform and Regression in Legal Reforms}

Beginning in the mid 1970s, anti-rape advocates enjoyed important legislative successes. They were able to convince state legislators to modify or enact legislation to expand definitions of rape to include instances of violence perpetrated by acquaintances or sexual partners. Legal reformers jettisoned the constraint of the "stranger rape" narrative-at least in terms of its codification in state laws and criminal regulations. This required two elements of legal change. First, reforms needed to dismantle the notion that rape occurs only at the hands of strangers in frequently violent episodes. The second was to reverse the requirement that victims of rape had to be "morally upstanding" women-women who were beyond repute (Adler 1987, p. 2). The first legal reforms, enacted in Michigan in 1974 and referred to as the Criminal Sexual Conduct Code (Caringella 2009, p. 13), included both elements. First, Michigan's reform law "shielded" victims from enduring interrogations about their sexual history-a modification that, within twenty years, had been replicated in every state (Hogan 2013). Overall, these "rape shield laws" protect women from being repeatedly subjected to traditional and outmoded notions of rape that limit state protections to only the most unimpeachable women. ${ }^{2}$

Second, Michigan's 1974 legislation tackled the myth of stranger rape by creating a scale of criminal sexual conduct. Severity would increase depending on the presence of "aggravating factors," among which included "blood affiliation" or shared housing between assailant and victim, or the degree to which the assailant held a position of "power, authority or trust" (Caringella 2009, p. 13). The landmark legislation also removed any requirement of corroborating testimony. One of the most troubling aspects of pre-1970s rape law was the requirement (unique to rape cases) that victims seek and produce witnesses that could substantiate their allegations-an imposition that rendered rape cases nearly impossible to successfully litigate (Caringella 2009). Although Michigan had never enacted

2 Of course, there are exceptions to this progress. For instance, in some states, a victim's sexual history is still relevant for establishing consent. 
a law requiring victims to corroborate their testimony, the standard enjoyed de facto acceptance by prosecutors and judges. Michigan's reforms explicitly codified the negation of any such requirement.

By the 1980s, most states had considered—and a lion's share had passed-reform legislation reflecting demands from feminist reform activists (Adler 1987, p. 4). Legislation has, for the most part, followed the Michigan model—providing some version of a "rape shield law" and removing corroborating requirements. States were slower to remove barriers to criminalizing spousal or acquaintance rape. Although the first state to litigate marital rape (Massachusetts) and the first state to revoke spousal exceptions (Nebraska) each did so in the late 1970s, exceptions for spousal rape stayed on the books until the mid-1980s. By 1983, 17 states had removed any barriers to prosecuting rapes that occurred within the confines of marriage.

The long fight, waged by feminist activists to reform rape laws, produced measurable gains. The concrete cumulative effect of legal reform-of rape-shield laws, the elimination of the marital exception for rape, the wholesale removal of force requirements from some rape statutes and the reconceptualization of force in others, the creation of new categories of rape, and so on-has been to bring rape out of the private. Through legal reform, activists transformed righteous outrage and experiences of sexual violence into legal scaffolding. Through legal reform efforts, what was once personal has become political.

However, as Caringella (2009) argues, there is a difference between enactment and enforcement in the context of rape law. There are sizable and significant lacunas that continue to burden victims. Although every state enacted some version of rape reform, many of the obstacles that had either discouraged victims of rape and sexual assault from reporting sexual violence or inhibited convictions remain in place. The "practically negligible" (Adler 1987, p. 2) reporting rates that had motivated feminists to call for reforms barely budged in the decades following the largely successful reform efforts. Arcane assumptions about rape, entrenched outmoded habits of mind, and more broadly, patriarchal order, persist, remaining stubbornly in place and intact-yet hidden by the veneer of change. As Susan Estrich (1987) notes, "looks can be deceiving".

First, many courts remain suspicious of women victims and protective of male defendants in precisely the kinds of cases that made their predecessors suspicious-cases that do not involve weapons or beating; that are concerned with friends, neighbors, or pickups; the cases of simple rape. The difference is that force has replaced consent or corroboration or unchastity as the primary doctrinal rubric for expressing that distrust. Second, efforts to expand the crime of rape to include wife rape have in many jurisdictions been met by the same distrust of women complainants and commitment to male sexual access that are at the core of the longtime exclusion of both wife rape and simple rape from the law's prohibitions. (pp. 57-58)

How did these reforms falter? For one, although legal reforms provide language for victims of sexual assault to leverage when attempting to seek justice for these crimes, the barriers to reporting remain intact. Studies suggest that women negatively perceive reporting processes and professionals. They fear reprisals by their assailants, the possibility of blame by police officers (Du Mont et al. 2003, p. 468) and health care or community providers (Campbell 2005, p. 56), and the intensive interrogation of their private sexual histories. Despite a shift in legal reforms that rejects the mythology of the "stranger rape," women perceive police officers as continuing to maintain the "classic rape scenario"— sorting crime and victim into "real rape" and "real victim" (Du Mont et al. 2003, p. 469). Researchers believe that the higher rates of reporting among women with visible physical injuries_- "bruises, lacerations, abrasions, bumps, internal injuries and/or fractures" (Du Mont et al. 2003, p. 478)—are a manifestation of the lingering legacy of these outdated and limiting conceptions of sexual violence. Injuries corroborate credibility and nonconsent. Without the twin indicators of force or resistance, questions posed by law enforcement personnel-about a victim's clothing, mannerisms, flirtations, or voluntary alcohol or drug use-are received by victims as assessments of credibility and character. These kinds of inquiries reify the only-recently-dismantled 
second-class status of sexually violent acts and the victims who carry their burdens. Consequently, many victims of sexual violence would rather stay quiet than subject themselves to the suspicions and interrogations of legal gatekeepers.

The compunction to stay quiet is especially alluring because of the second limitation of litigation: the low probability of prevailing in court. One can imagine a victim of sexual assault finding the courage to report the crime- exposing themselves to the ongoing degradation of interrogation and evidence collection -if there existed a decent probability of formal legal outrage on her behalf. However, there appears to be little payoff to enduring the potential humiliation of reporting. ${ }^{3}$ In fact, pursuing legal remedies may only subject victims to further debasements of their character.

To a degree, the limits of law in adequately responding to rape cannot be squarely blamed on the content of legal reforms. Constitutional commitments to due process require that courts pay attention to the burdens placed on individuals accused of crimes. Due process obligations place constraints on individuals making allegations of rape and sexual assault. They impose evidentiary burdens that challenge attempts for legal reforms to protect victims from having to corroborate their claims or divulge sexual histories and behaviors. The private nature of many sexual assaults, particularly those committed by spouses, partners and acquaintances, means that legal conflicts may end up devolving into "he said, she said" disputes-which, without evidence, will inevitably come down to a question of credibility. This, coupled with a constitutionally-mandated presumption of innocence, means that any legal claimant of rape will have a difficult time proving their assailant's guilt.

This reveals a third, and potentially devastating, cost of legal intervention: interpretations of guilt and innocence in the context of rape cases. Unlike other crimes-theft, assault, and murder, for instance-assignments of guilt in rape and sexual assault cases largely hinge on interpretations of a set of agreed-upon facts. In most cases, there is little doubt as to the fact of the sexual act or the actors involved. Where the victim and assailant differ is in regards to assessments of consent. The claimant believes that she did not consent to the sexual interaction, that she made that fact clear through verbal and/or non-verbal cues and that the accused persisted or forced her to continue despite her contestations. Most importantly, the claimant perceives the non-consensual sexual act itself as an egregious physical assault and a profound violation of her bodily autonomy. The accused, on the other hand, believes either that both parties consented to the sexual act or, at the very least, that the victim's nonconsent could not have been reasonably perceived. He believes that no assault occurred-that the sexual act imposed little harm. If she prevails, the accused will be punished and the victim's version of events will bear the legitimacy of law. If she does not-a far more frequent outcome-she will, at the very least, be charged as having "overreacted," but more likely will be labeled a liar.

In all, this suggests that, even without a societal commitment to the "stranger rape" narrative, claimants making rape accusations will face an uphill battle that exposes them to potentially discrediting accusations. However, the narrative of the "stranger rape" persists. Baked within the reforms-and nested within the mandates of the rule of law-are the vestiges of gendered expectations and impositions regarding sexuality and sexual expression.

\subsection{Mechanisms of Regression in Rape Law}

Gendered expectations, which take root, in part, in rape laws and exemplify the enduring salience and everyday power of patriarchal logics, have a long, branching history. Broad general legal surveys, which address the statutory construction of rape within the early American, or English context, often bring elements of this history into focus. For example, in American Law in the 20th Century, Lawrence Friedman (2002) remarks on how "ancient stereotypes" about "an unchaste woman" have historically

3 The Rape, Abuse and Incest National Network (RAINN) estimates that only 7 of every 1000 instances of rape or sexual assault will lead to a felony conviction and only 6 will result in a perpetrator serving prison time-the lowest rate of incarceration for any crime committed in the United States (www.rainn.org). 
embedded legal processes around rape (p. 249). The operations of this stereotype are especially visible when victims' sexual histories are used as a pretext to contravene justice, a now-obsolescing practice following the widespread enactment of rape-shield laws. Similarly, in their primer on feminist legal theory, Nancy Levit and Robert Verchick (Levit and Verchick 2016) relay the widely-cited fact that "Early Anglo-American law considered women to be a property of their fathers or husbands. Rape by a stranger was thus considered 'a property crime of man against man'” (p. 192). Arcane views of women qua property survived in statutes that carved out a marital exception for rape, discussion of which resurfaced during the 2015-6 U.S. presidential campaign (Dreyfuss 2015). As established above, these statutes have been dismantled. Nevertheless, this understanding lives on in "some states" where "marital rape [is] a less serious crime than nonmarital rape" (Levit and Verchick 2016, p. 192). However, a long history of rape law must also contend with force, a resilient feature of statutory constructions of rape, which, as underscored in Section 5.1, enduringly structures and potentially constrains everyday responses to sexual violence.

Force is a sine qua non of the mythological rape. Although states have slowly ejected this premise from rape laws, as already elucidated above, the premise and expectation of force continues to shape and affect how criminal justice systems, and their agents, address rape and victims of sexual violence (Campbell 2005; Du Mont et al. 2003; Frohmann and Mertz 1994). That this is so should be unsurprising. Popular narratives and depictions of sexual violence often emphasize force. News stories replicate, promulgate, and, in so doing, re-sediment mythological rape narratives, re-establishing their purchase and directing public understandings of rape. Likewise, this narrative is relayed and reiterated on and through television and in movies. There is nothing unfamiliar about the mythological rape. However, what is sometimes elided in treatments thereof is how the features of this mythology came to be set in place.

Within the expectation of force in rape manifests a complicated history. Surveying early Anglo-Saxon law treating rape, Zsuzsanna Adler (1987) echoes a familiar point, noting "the offence also had a strong property aspect to it," and that "rape in Anglo-Saxon law included abduction as well as forcible sex" (p. 20). These laws underwent several revisions, which makes any discussion of them as a single "package," embodying a single consistent structuring logic, challenging. At the same time, certain features of these laws have shown to be historically resilient, and have endured through time. In particular, the idea of force in rape flows and is, in part, inherited from these bygone statutes.

Julia Quilter (2015) shows how this idea and expectation, originating in early English statute, was woven into and reproduced in the work of seventeenth- and eighteenth-century jurists. In the process of interpreting and codifying the ancient statutes, these jurists interpolated contemporary meanings of rape into these laws. That is, seventeenth- and eighteenth-century jurists retrojected (then) contemporary understandings of rape back onto the noun raptus, which, as deployed within the context of early (twelfth and thirteenth century) English statutes, exhibits polysemic qualities, and fails to perfectly square with "rape" (Quilter 2015, pp. 97-98). Quilter notes that, within this early context, the boundary separating property and sexual crimes was "blurred." During this period, raptus, writes Quilter, was a flexible and unstable signifier. Notably, this term was applied "in many instances" in which "the nature of the offence" was "either 'rape' or abduction, or rape and abduction." However, "where case[s] only use rapuit or raptus it is truly impossible to tell what the primary offense was, ultimately recognizing that raptus in the Middle Ages covered a diversity of experience from consensual love affairs to violent rape" (Quilter 2015, p. 97). For example, "ravishment statutes ... effectively blurred what I call the 'property' crime (of abduction and elopement of women) and what appears to be a more specific focus on a 'sexual' crime in the appeal of raptus" (Quilter 2015, p. 99).

These lexical nuances were lost on seventeenth- and eighteenth-century jurists. Rather than engaged in Wittgensteinian investigations, these jurists interpreted and systematized these statutes in ways that conformed to contemporary understandings (and uses) of rape. That they did so and were insensitive to the context and complicated semiotic purchase of raptus is problematic for us, argues 
Quilter. Although writing for an Australasian audience, Quilter's observations hold for American rape laws and American experiences around and related to rape. Quilter writes,

I have shown that the emphasis on resistance and injury, which has persisted through decades of attempts at statutory erasure, was the product of re-writings of the elements of "rape" from the older marriage and property laws. Thus, the old rapuit emphasize the force necessary to "carry away" a woman, to the detriment of the father's or husband's property interests, whereas in modern times the notion of "force" was redeployed with respect to the overpowering of the woman's will ... The commentaries [codified by early-modern jurists] thus consolidated a notion of the "true" rape that, despite rape's formal characterization as a crime of sexual violation, perpetuated requirements drawn from rape's history as a property crime protective of patriarchal interests. (Quilter 2015, p. 111)

In other words, the expectations, facts, and normative underpinnings and aims of ravishment (which involves the literal "carrying away" of a woman and violating the property interest of men), were stitched into seventeenth- and eighteenth-century legal treatments of rape. "As a result," writes Quilter (2015), "women continued to have the authenticity of their claim that they had been raped judged with reference to old requirements (force, physical injury) that were at odds with the law's 'new' concern with sanctioning sexual violation" (p. 111). This understanding, which connects force and rape, endures, even though this formulation and idea of rape-a formulation enshrined in the works of classic jurists such as Coke and Blackstone-often cannot be mapped onto real, lived experiences of sexual violence.

Even if rape laws now do not uniformly organize around the premise of force, the mythological rape (or in the familiar parlance of Susan Estrich, "real" rape) continues to inform rape statutes. "In almost half the states," writes Stephen Schulhofer (2017), "sexual penetration is not a crime unless there is both non-consent and some sort of force" (p. 342). In other words, Schulhofer (2017) continues in bold, "Penetration without consent is not, itself, a crime" (p. 343). ${ }^{4}$ Moreover, this idea continues to circulate in popular discussions of rape, whether as an unstated premise or as a conclusive point. In so doing, it oft limits understanding of consent and narrows views of what rape is or how it ought to be defined. As already highlighted, even within statutory contexts where the requirement of force has withered or fallen away, this expectation stubbornly remains in the attitudes of legal officials. Whether there is a legal emphasis on consent exclusive of force or not, the link between force and rape endures.

For states that have reconsidered force requirements in rape laws, consent (variously defined) has become a dividing line between sex and rape (Noveck 2017; Tracy et al. 2013). This is a productive statutory shift, whose effect is to broaden definitions of rape and make statutes more sensitive to lived experiences of sexual violence. However, in the absence of a single, uniform national standard for rape, there is a maze of rape statutes-a patchwork of laws whose many parts and premises do not always jibe and harmonize. What counts as rape in one jurisdiction may not be considered rape in another.

In 1986, Susan Estrich delineated two paths for legal reformers. "Feminist reformers seeking to protect women from such threatening situations have only two choices," she writes. Reformers can "focus on the man and seek to redefine what is meant by force in broader terms; or ... focus on the woman and rely on her word as to nonconsent, properly defined (not saying yes, or at least saying no)" (Estrich 2008, p. 208). Each option, Estrich relays, has its critics. Nevertheless, traces of these logics reside in many contemporary rape laws.

On the whole, it is for these reasons that many victims perceive legal contact of any kind as a "second assault" or a "second rape" (Campbell 2005, p. 56) and why scholars argue that hard-won legal

4 The Women's Law Project/ ÆQUUTAS report “Rape and Sexual Assault in the Legal System," published in 2013 and cited by Schulhofer, includes Alabama, the District of Columbia, Kansas, Florida, Mississippi, Missouri, Nebraska, Nevada, New Hampshire, New York, Oregon, Pennsylvania, South Dakota, Tennessee, Utah, Vermont, and Washington in its list (Tracy et al. 2013, p. 20). 
reforms have done little to alter the scripts we use to perceive and describe sexual violence. The intent of legal reformers was to expand the space and scope of traditional rape doctrines to exclude reliance on the victim's moral character and to include acquaintance rape. However, reform activists did little to alter how rape is conceptualized or concretized. As Kristin Bumiller (1987) asserts, "Both traditional rape law and the feminist law reformers share a vision in which the boundary between sex and rape is defined by the woman's nonconsent" (p. 76). The expectation of force and the fallacy of agency only serve to propagate traditional notions of rape. The stranger rape remains the benchmark of a real rape (Bumiller 1987, p. 77). It is the job of the victim, and their lawyer, to curate a narrative that most closely approximates this image. It is this failure of the law-the stagnant reporting and conviction rates, the ongoing intrusions into a woman's sexual history, the automatic skepticism of victims, and the unyielding focus on force-that prompts Caringella (2009) to argue that "reforms have largely served a symbolic and educative function" (p. 2).

\section{Speaking Up and Speaking Out}

Anti-rape activists did not limit their efforts to legal reforms. Alongside feminists working to alter the standards of adjudication in cases of rape and sexual assault, activists also pursued a second, co-equal strategy: to create spaces, opportunities, frames, and concepts to help survivors break out of their isolation and to see their personal experiences more broadly as an assault on women's bodies. While legal reformers focused on making criminal sanctions more accessible and palatable to victims of sexual violence, consciousness-raising activists tailored their efforts to help victims break their silence. At first blush, these coterminous approaches may seem mutually reinforcing. Modify legal procedures to help rape victims make claims in court and you logically open up the space for more people to talk about their experiences. Increase arenas for victims to share their experiences and, together, there is greater demand for and use of legal redress. However, it quickly became apparent that the two strategies were at odds. Although legal reformers worked to provide a space where the claims of rape victims could receive the backing of law, the language of legal rhetoric did not go far enough to embrace the varied experiences of sexual violence. Argues Bumiller (1987), "goals, framed and fashioned in the confines of the legal system and liberal legalistic reform, inhibited feminists from moving beyond this 'restricted' definition of rape to phenomenological accounts of victims' experiences that did not easily flow from the framing of events" (p. 78).

This incongruity in approaches has significant implications. Victims of sexual violence experience multiple violations and require interactive interventions to heal. In addition to the physical pain associated with the assault-those emanating from both the violent sexual act itself and any accompanying physical attacks—sexual violence imposes multiple ongoing, and often compounding, hardships. First, the type of violation-the overpowering of one's body and the perversion of routine, intimate and pleasurable acts to impose control and inflict pain-renders sexual violence especially difficult to overcome. Second, in many instances, the physical indicia of sexual violence are invisible to the naked eye. In a typical physical altercation, people see the indicators of violence-bruises, a black eye, a laceration, etc. These visible manifestations of violence make the fact of the violation self-evident-and make it easier for victims to seek and receive support and empathy. In cases of sexual violence, the absence of "evidence" - the lack of outward markers of struggle-makes it more difficult for victims to receive support. They are either forced to resolve, on their own, the cognitive dissonance of appearing unharmed while feeling brutalized, or risk being accused of lying or exaggerating when they seek assistance. When sex becomes rape-when sexual intimacy is recast as violence-victims are required to find ways to both incorporate this new possibility and distinguish between these two versions of the same act. Without the opportunity to find and engage in forms of mutual validation-to see in others that their own understanding of their experience is accurate and legitimate-victims of sexual violence will process their assault through mutually-reinforcing and destructive lenses of fear and self-doubt. 
Anti-rape activists understood that isolation compounds the effects of sexual violence. By meeting others who had experienced some form of sexual violence, victims could begin the process of realizing that theirs was "not just an individual and unique experience" (Cuklanz 1996, p. 3), but one shared by countless others in myriad ways. Activists sought to craft spaces and strategies to help victims turn their blame away from themselves and towards their assailants and the societal forces and structures that legitimate and facilitate the use of sexual contact as a means of coercion and control. In this way, consciousness-raising is more than just talking or expressing. Through reciprocal interactions of talking and listening, receiving and engaging, survivors of sexual violence construct a shared understanding of sexual coercion as a "social problem" requiring a collective response. According to Miranda Fricker (2007), the "process of sharing these half-formed understandings awakened hitherto dormant resources for social meaning that brought clarity, cognitive confidence, and increased communicative facility" (p. 148).

Whereas legal reform focused on expanding the zone of credibility for rape survivors, consciousness-raising activists worked to reveal how sexual violence is experienced to redefine how sexual violence is understood. Consciousness-raising activists understood that, to achieve their specific goals-helping survivors to "construct a [sense of] reality" that accounted for their assault and to "circulate that reality as widely and smoothly as possible throughout society" (Cuklanz 1996, p. 6) - they had to establish a specific approach. After all, consciousness-raising in the context of sexual violence requires different forms and forums of exchange and expression. Acts of deliberation or debate, for instance, rely on discussion and discourse as a means of amassing complementary or competing perspectives to identify consensus or to promote compromise. In deliberative spaces, a premium is paid to the free exchange of ideas-so long as all who are participating are given the option to freely articulate their positions. Public hearings exemplify this approach.

Consciousness-raising serves a different purpose and requires a different set of norms and features. The goal of consciousness-raising is not to provide a forum for debate or deliberation-or for evaluating or dissecting incidences of sexual assault. Neither is the purpose to exact justice against the perpetrators. Instead, consciousness-raising safeguards spaces for survivors to tell their stories. Whereas deliberative spaces are structured to promote consensus and agreement between multiple incongruent perspectives, consciousness-raising focuses on empowerment and healing and will privilege only one voice-that of the survivor. Consciousness-raising attempts to illuminate and share the widespread and varied experiences of sexual violence to empower survivors and to expose the structural and social supports that scaffold ongoing (and increasing) incidences of sexual violence. Advocates curate spaces specifically to avoid reifying traditional conversations about rape in which it is perceived as acceptable to evaluate claims of sexual violence and to treat them as private, individual, and aberrant. Instead, consciousness-raising seeks to promote empathy for survivors and to view sexual violence as collective, frequent and dehumanizing (Kelland 2016).

Speak outs embody the principles of consciousness-raising and the requirements of empathic listening. Performed frequently on college campuses or in other public settings, speak outs provide a mechanism for victims of sexual assault to declare their experiences both as a way of pushing back on the debilitating effects of sexual violence and as a way of contributing to a collective confirmation of the prevalence of this violence. Among the most critical ingredients, therefore, is a commitment to establishing norms of support, empathy, and acceptance. Speak outs, then, are operating according to a logic that is incompatible with the principles that govern courts of law. In a court of law, witnesses tell their story to provide evidentiary support for their allegations. Legal actors and onlookers are free to evaluate these claims - and to measure them against other forms of evidence. In a speak out, survivors tell their stories to empower, uplift and testify to the ongoing problem of sexual violence. Contestation is not only inappropriate and valueless, but can also be destructive.

\section{\#MeToo as Consciousness-Raising}

A survey of \#MeToo reveals how it fits within and relates to the longer tradition of consciousness-raising efforts, highlighted above. Indeed, \#MeToo discourse carries within it many of 
the elements, logics, and goals that shaped and structured the use of consciousness-raising to navigate, connect, and process experiences of sexual violence. \#MeToo cannot be reduced to, nor is it selfsame with these consciousness-raising efforts. At the same time, like consciousness-raisers, the \#MeToo movement, at its best, resists and reveals the imprint of legality, the everyday use of legal concepts and standards, models of legal procedure and legal process, while relating to victims of sexual violence. At its worst, we argue, \#MeToo and responses to it, reify ideas of "stranger" rape, reproduce legal understandings of sexual violence, transpose evidentiary burdens and legal standards (such as due process) from the courtroom to the public square, and impose parameters in order to taxonomize variable experiences of sexual violence-to draw distinctions between "bad sex" and "real" rape.

At a moment when it was still nascent, Sophie Gilbert (2017) summed up the \#MeToo hashtag movement this way:

Unlike many kinds of social-media activism, it isn't a call to action or the beginning of a campaign, culminating in a series of protests and speeches and events. It's simply an attempt to get people to understand the prevalence of sexual harassment and assault in society. To get women, and men, to raise their hands.

The movement is not simply a dipstick, used to measure the pervasiveness of sexual harassment and sexual assault. Rather, like other forms of consciousness-raising, \#MeToo exists to prove a point. It reveals something already known to many women and men. However, it does not, nor did it, stop here. Even if in the first instance a call for "women, and men, to raise their hands," the movement quickly reached beyond this founding goal.

Activists loaded \#MeToo with new purposes and aims. The \#MeToo movement became plural, as writers fabricated associational links that connected this movement to any one of several (usually interlocking) issues and outlooks. "The \#MeToo movement is one more wave in a long line of feminist calls for careful attention to how women spend their time and energy each day, and one more reminder that women's expenditures should not be significantly larger than men's," writes Sara Maurer (2018). With a similar emphasis on labor and work, \#MeToo, relays Sarah Seltzer (2017), makes plain the inadequacy of "lean in" philosophy. ${ }^{5}$ The assumption that embeds this philosophy, that "workplaces are fine just as they are," crashes up against the hard reality of workplaces as they are. "As many of us knew all along but are seeing even more clearly now, workplace inequality isn't about a problem deep within ourselves. It's about the sexist, exploitative hyper-capitalist minefield that comes with working in 2017," argues Seltzer.

Circulating through these assessments of \#MeToo is an obvious revolutionary design and fervor. This design is cleanly captured in Charlotte Shane's Splinter article, "We Harpies Want More." "Firings are not enough," Shane (2018) writes. \#MeToo is about sexual harassment, sexual violence and predation, but it is about more too. "The post-Weinstein moment isn't a war on sex. It's a long-overdue revolution" (Flanagan 2017). The proliferation of \#MeToos in social networks trains attention to the conditions that make sexual violence possible. That is, the spread of \#MeToos across all social media "channels" draws attention to structure- to the design of institutions and the content (and organizing principles) of culture. As situated by some commentators, \#MeToo, the problem of sexual violence, cannot be treated without also addressing a system that licenses other forms of overlapping oppression and violence. \#MeToo, for these commentators, intersects with and is inextricably connected to a raft of other issues and causes, prominent among which are racial and economic justice. Shane (2018) puts it this way:

Instead of taking victory laps, we've been reminding each other that we need to turn our attention to domestic workers, and to men who've been violated; that the core problem is

5 An idea made famous by Sheryl Sandberg in her 2013 book Lean In: Women, Work and the Will to Lead, New York: Alfred A. Knopf. 
not sex but work, and not sex but authority; that to disregard or otherwise erase race is to render any so-called progress worthless; and that the firings are not nearly enough.

However, what remains to be seen is how or if \#MeToo has recast our world. As the New Yorker's Jia Tolentino (2018) highlights, a backlash is coming. There is talk of "sex panics" (Geesen 2017), violations of "due process" (Panahi 2017; Yoffe 2017), victim-scripts (Fargo 2017), denials of agency (Rothschild 2017), "witch hunts" (Dalmia 2017), and a "blurring" of lines between legally-distinguishable forms of sexual violation (Geesen 2017). \#MeToo may yet survive this backlash. At the same time, the movement \#MeToo spurred may be without sufficient endurance to realize the aims some commentators envisage for it.

Calls for "due process" and counter-hashtag campaigns are frequently used to minimize, invalidate, and erase the experiences of sexual violence reported by women and men. Within these calls, legal concepts are fused with everyday understandings and often inform evaluations of sexual violence. In the context of the \#MeToo moment, legal discourse operates in ways that potentially forestall discussion and cut off conversation that would interrogate experiences of sexual violence and draw these experiences into a larger, social frame. Further, working within this discourse, and invocations of "due process," is an assumption and an expectation that normal legal pathways are clear of obstacles for victims of sexual violence, when in fact these pathways are ridden with obstacles and peril.

However, these calls and hashtag uses are now pitted against a movement that puts stock in victim reports. It is true that \#MeToo may be a watershed. Accompanying \#MeToo has been an adjustment in how reports of sexual violence are received in the public square. As much as "Believe All Women" is invoked with more than a tincture of skepticism by some commentators, this shift in terms of how the credibility of victims is addressed in the public square represents a reversal. Critics who contend "due process is better than mob rule" miss the point (Weiss 2017). The aim, and point, is not (or is not always) criminal prosecution. "In the 1970s-and still today, I might add — such acts of speaking out are usually defined by feminists as 'agency'—an active defiance and resistance to the patriarchal prescription of silence and shame," notes Dubravka Zarkov (Davis and Zarkov 2018, p. 4). \#MeToo, in part, encourages resistance to this prescribed silence, and inoculates against patriarchy-inscribed shame by linking experiences of sexual violence-by de-privatizing these experiences, and making them part of a larger, public narrative. In this sense, \#MeToo represents an exercise in consciousness-raising. One metric by which to measure the success of \#MeToo is structural change. An obvious goal of many \#MeToo activists is change at the system level. However, another metric is the extent to which \#MeToo inspires conditions in which speaking out becomes normal and possible in the absence of social sanction and stigmatization. Notably, these two metrics and goals cannot be disentangled. "[A]gency has always been important for feminism precisely because it is more than an individual capacity; rather, it is practice that is instrumental for social change," remarks Zarkov (Davis and Zarkov 2018, p. 4). However, it's here that the potential limits of \#MeToo become noticeable.

As stated above, Me Too was created by Tarana Burke "to 'let other survivors know they are not alone' and create solidarity with the victims" (Davis and Zarkov 2018, p. 3). The solidarity and community that results from a hashtag movement may be of a qualitatively different kind than what resulted from feminist-led movements of the 1970s. These latter movements used consciousness-raising to forge durable links between women and to develop communities of praxis.

Within the \#MeToo moment intersects countless others. These others form the context for \#MeToo, but also embed within it, and help to shape both it and responses to it. From the outset, \#MeToo was posed as a response to the Harvey Weinstein scandal. Thus, while focused on experiences of sexual violence, there has been, throughout, an unrelenting focus on individuals. This emphasis sometimes overwhelms other aspects of the movement, and may siphon off some of the movement's more radical energies. Although not necessarily mutually exclusive, this emphasis on individuals-the testimony of individuals, individual (often celebrity) perpetrators-may work to cross-purposes with the ambition of forging a movement that creates durable links of solidarity and encourages collective activism. 
As Kathy Davis puts it, what distinguishes \#MeToo from some other movements, such as Take Back the Night, is that the latter

kind of activism does not focus on the testimony of individual woman, but frames sexual violence as a collective issue facing all women, which requires raising public awareness and involving both women and men in grass-root activism as well as transforming institutions which condone violence against women. (Davis and Zarkov 2018, p. 5)

Furthermore, venue and medium may matter. Forming interpersonal links and creating intersubjective, shared meanings and understandings may be more easily accomplished in person than it is through social media. The links and meanings that result from the one may be more durable and lasting than what results from the other. This is not to say that hashtag activism does not produce effects in the world. It is also not to suggest that social-media activism cannot spur grass-roots activities aimed at sweeping social and political change. Experience supplies varied demonstrations that it can. However, the experience of proclaiming "\#MeToo" online and making this proclamation within the context of something akin to a speak out may be qualitatively different, and may produce different effects. Paradoxically, \#MeToo may unite by creating digital connections, and, at the same time, atomize by substituting these digital connections for their real-world, analog equivalent.

However, the limits of online organizing ought not be overblown, nor should these new patterns of activism be exclusively assessed with reference to old templates and expectations about what activism is. While the legacy of \#MeToo remains unclear, what is clearer is how movements such as \#MeToo can contribute to and spur forms public discourse that may operate as a kind of antidote to the "patriarchal prescription of silence and shame." However, the extent to which this is so is unclear. Whether \#MeToo will result in permanent adjustments in how reports of sexual violence are received in the public square remains an open question. Nor is it clear that the forms of communication \#MeToo inspires are desirable and productive. The \#MeToo wave may yet recede. Nevertheless, if and when it does, it is likely the landscape that is revealed will be changed in some ways, but not others.

\#MeToo may remake some features of our social and political environment. It may also contribute to the development of new social and political forms and new patterns of habit that vitiate some effects and the operations of legality on responses to sexual violence. At the same time, legal concepts frequently appear in \#MeToo discussions, which often develop with reference to binaries and ways of thinking that further sediment legalistic understandings of (and reactions to) sexual violence. For example, within responses to the \#MeToo movement and reactions to the claims of victims can be found an emphasis on legal taxonomy. Is this sexual harassment? Is that rape? Further, even where commentators aim to decouple and disaggregate understandings of sexual violence from legal standards and benchmarks, the new understandings of sexual violence that result are sometimes developed in reference to, and so reproduce these benchmarks and standards.

\section{Law's Limits in Public Discourse}

Even outside of a courtroom, law supplies normative benchmarks and puts down parameters that can narrow one's vision of and regulate responses to sexual violence. Regardless of where conversations about sexual violence occur-or to what end-law has the potential to cast a shadow on the experiences of victims. When this happens, there is a double effect. First, these experiences are drawn into comparison with legalistic notions of sexual violence and sexual violation. Second, the disjunction between lived experiences of sexual violence and relevant legal benchmarks becomes a justification to invalidate and disregard the former lived experiences. These "effects" are especially prevalent and visible in two case examples. The first example considers responses addressed to Aziz Ansari's interactions with a woman known as "Grace." The second examines responses to an Obama-era survey. The purpose of the survey was to furnish baseline statistics wherewith to make sense of and roughly capture the prevalence of experiences of sexual violence. 


\subsection{Grace}

A recent story published by babe.net-in the midst of \#MeToo-recounts a date, and what followed it, between Aziz Ansari and a woman referred to in the report as "Grace." Julianne Escobedo Shepherd (2018), of Jezebel, offers this précis.

... Babe.net published a detailed account of an encounter between "Grace," an anonymous 23-year-old photographer, and the actor Aziz Ansari. It described a September 2017 incident in which Grace says that she and Ansari went on a date after first meeting at an Emmys afterparty, and how, at the end of the date, Grace said Ansari coerced her into sexual behavior that was well beyond her boundaries, ignoring her verbal and nonverbal attempts to stop their sexual exchange.

Some commentators, after parsing the facts of Grace's story, simply attach a label of "bad sex" to the account, and then move on to excoriate babe for promoting a narrative and story that drains women of agency and even for distributing "revenge porn" (Flanagan 2018). Bari Weiss' treatment in "Aziz Ansari Is Guilty. Of Not Being A Mind Reader" travels in this vein. "If he pressures you to do something you don't want to do, use a four-letter word, stand up on your two legs and walk out his door," writes Weiss (2018). Caitlin Flanagan also travels this path. Flanagan presents a model of sexual coercion that should, by now, ring troublingly familiar. Harkening on different times, Flanagan (2018) recalls, "[if] a man tried to push you into anything you didn't want, even just a kiss, you told him flat out you weren't doing it." She goes on,

They told you to do whatever it took to stop him from using your body in any way you didn't want, and under no circumstances to go down without a fight. In so many ways, compared with today's young women, we were weak; we were being prepared for being wives and mothers, not occupants of the C-Suite. But as far as getting away from a man who was trying to pressure us into sex we didn't want, we were strong.

With this passage, Flanagan puts down foundations for and telegraphs the larger argument: "Apparently there is a whole country full of young women who don't know how to call a cab, and who have spent a lot of time picking out pretty outfits for dates they hoped would be nights to remember" (Flanagan 2018). At the same time, the scenario Flanagan sketches above becomes a normative slide-rule against which experiences of sexual violence are weighed and considered. This scenario reproduces the expectation that force-and resistance-accompanies or ought to accompany sexual violence. To be fair to Flanagan, this is not her point. However, nested within a string of claims that appear to chide today's "young women" for failing to be "strong," this passage construes Grace as complicit, and her experience merely one of bad sex.

Flanagan goes on to relay that Grace's claims cannot be supported by a reconstruction of the facts.

Was Grace frozen, terrified, stuck? No. She tells us that she wanted something from Ansari and that she was trying to figure out how to get it. She wanted affection, kindness, attention. Perhaps she hoped to maybe even become the famous man's girlfriend. He wasn't interested. What she felt afterward—rejected yet another time, by yet another man—was regret. (Flanagan 2018)

Flanagan parses the details of Grace's account, the circumstances around the encounter, and offers a verdict. Is this sexual assault? No, she reasons. Digging through the contents of Grace's story, Flanagan is unable to isolate the elements and hallmarks of true sexual assault. However, this finding altogether elides Grace's perspective and makes Grace a bystander in this process of adjudication. Flanagan overlooks Grace's experience of violation, and, in so doing, substitutes a version of the prototypical, mythological rape in its place.

Weiss' commentary organizes around a similar set of plot points. Weiss (2018) contends, 
But the solution to these problems does not begin with women torching men for failing to understand their "nonverbal cues." It is for women to be more verbal. It's to say, "This is what turns me on." It's to say, "I don't want to do that." And, yes, sometimes it means saying goodbye.

She later continues,

To judge from social media reaction, they also see a flagrant abuse of power in this sexual encounter. Yes, Mr. Ansari is a wealthy celebrity with a Netflix show. But he had no actual power over the woman-professionally or otherwise. And lumping him in with the same movement that brought down men who ran movie studios and forced themselves on actresses, or the factory-floor supervisors who demanded sex from female workers, trivializes what \#MeToo first stood for. (Weiss 2018)

Within these two passages circulate normative precepts transposed from the law and legal understandings of rape. In the first instance, Weiss specifies what counts, and does not count for consent. "It's to say, 'I don't want to do that,'" Weiss explains. "Nonverbal cues," however, are too opaque, inscrutable, and difficult to puzzle out. "It is for the women to be more verbal." The implication Weiss makes is troubling: a sexual encounter cannot be assault in the absence of an "I don't want to do that." Such a sexual encounter lands somewhere else in that typology. In the taxonomy of sexual experiences, this is "bad sex." Likewise, Vox writer Alexia Fernández Campbell (2018) evaluates, "Some-like the Aziz Ansari story-are more clearly in the realm of gross (if legal) behavior."

In the second passage, Weiss puts in place another foundational plank that supports her ultimate finding. Ansari "had no actual power over the woman—professional or otherwise." This is a categorical statement-it admits no alternative possibility. Ansari simply "had no actual power." Weiss loads "power" with weight, and implies that proper application of the criterion of power yields a different finding about Grace's experience. It would be wrong to "lump" Ansari in with figures such as Weinstein, who wield real power-who have access to a deep well of financial resources, social and political capital. It is important to grapple with the ways in which power makes sexual coercion, sexual violence, possible. But Weiss' narrow specification of power allows her to read coercion out of Grace's story and disregard the "social media reaction" which sees "a flagrant abuse of power in this sexual encounter." It also allows Weiss to disregard Grace's stated experience.

Ansari instructed her to turn around. "He sat back ... and motioned for me to go down on him. And I did. I think I just felt really pressured. It was literally the most unexpected thing I thought would happen at that moment because I told him I was uncomfortable." (Way 2018)

That Weiss disregards Grace's experience is unsurprising. Weiss' op-ed is calibrated to different aims. It was not written with the goal of sharing the experience and forging connections. Its purpose is to arrive at a finding of fact, to evaluate and judge the experience. "Aziz Ansari is Guilty," Weiss' article announces, "Of Not Being a Mind Reader." Of what, then, is Ansari not guilty? Weiss' answer is clear: sexual assault.

Others have used Grace's experience with Ansari to, as Stassa Edwards (2018) puts it, "map the wilderness of bad sex." Commonplace notions of consent fail to square with the actual content of sexual experiences. Norms and expectations about sex, it is argued, are in need of thorough revision. "Bad sex can be an uncomfortable moment or a forgettable night, but it can also be an experience that lingers for decades, forming the core of personhood," explains Edwards (2018). "The refusal to untangle consent leaves us with, as Grace says, in a state of confusion with the need to 'validate' experiences that exist in the chasm between 'bad sex' and sexual assault." What \#MeToo must do, Edwards (2018) charges, is "enter the chasm and map its boundaries and label what resides there. It needs to ask whether or not we're content with the physical and narrative shapelessness of the chasm." In this way, Edwards' excellent treatment connects to a larger tradition whose raison d'être is to, as Edwards puts it, bring order to a "state of confusion" and "validate" the experiences of victims 
of sexual violence. In particular, Edwards constructs an analysis around Kate Manne's, whose work, as Edwards notes, pries open and theorizes this chasm, delivering analytical and taxonomic tools that can be used to capture a range of experiences that fail to square with "legal definitions of sexual assault and rape" (Edwards 2018).

Ann Cahill, responding to and building on the work of Nicola Garvey, theorizes in consonant (but not selfsame) patterns, and aims to subject these "ethical gray areas" to philosophical scrutiny (Cahill 2016, p. 757). Like Manne, Cahill uses novel conceptual tools to categorize and make sense of sexual interactions that fall into an interstitial chasm, similar to the one Edwards describes. In particular, Cahill (2016) acknowledges

the fact that these interactions are constructed in the social imaginary as part and parcel of normalized heterosex, while at least some forms of sexual assault are constructed in the social imaginary as aberrant and worthy of social condemnation, indicates that the different phenomena may not only function differently in terms of their social and political meanings, but also may carry distinct ethical meanings to the women who experience them. (p. 752)

Cahill granularly unpacks the content of these experiences (as presented by Garvey), and in so doing, grapples with the complicated ethics of "unjust" heterosex. Importantly, Cahill, rather than projecting a meta-narrative onto these experiences and disregarding the claims of women, takes these claims seriously. As Cahill points out, the experiences recounted by women, which although are part-and-parcel of normalized hetereosex, generate confusion and are themselves ambiguous. This ambiguity, writes Cahill, "the ways in which, from the perspectives of the women who experienced them," these experiences "seemed to fit into neither the category of clearly ethical, consensual sex or that of clearly unethical, nonconsensual sex-is central and persistent" (Cahill 2016, p. 751). Cahill's treatment is neither hemmed in nor bound by legal distinctions and a legal understanding of rape (Cahill 2016, pp. 758-59). Nevertheless, it is possible that legality is at work and operative in the experiences of the women with whom Cahill (Garvey too) is concerned. Whether these taken-for-granted (legal) boundaries and distinctions produce ethical grey areas as of the sort Cahill studies is an open question. Although a matter that requires focused study, it is plausible that the frustration, ambiguity, and confusion that accompanies sexual experiences that occupy this seeming middle ground may be, in part, an effect of the operations of legality.

Edwards also attempts to escape legal distinctions and legal understandings, however, may inadvertently reproduce both. On the one hand, Edwards is clear that one's sense of sexual violation ought not be tied to or informed by legal understandings. She (Edwards 2018) explains,

That Grace is trying to navigate this chasm is clear, but it is an uncharted wilderness in many respects, marked only with warnings that entry is dangerous, perhaps even perilous. Consent is the technical boundary to the chasm — which, in theory, should protect us from tumbling to its ground-a legally drawn line dividing sexual assault and an "awkward sexual experience." But even this line is not as evident as, perhaps, it should be.

Edwards theorizes experiences of sexual violation with an explicit eye to escaping the strictures of legal distinctions and troubling the illusion that, in Edwards' words, the law offers clear-cut, vividly demarcated boundaries between "sexual assault and 'an awkward sexual experience."' However, even here, legal benchmarks provide scaffolding-a set of reference-points used, in one way or another, to make sense of and come to grips with experiences of sexual violence. Edwards' evaluation may naturalize existing legal understandings of "sexual assault," which represent one pole at one end of the chasm in which Edwards is interested. At the same time, Edwards' commentary, and perhaps Cahill's work too, draws into focus tensions and ambiguities that put into relief how lived experiences of sexual violation fail to square with statutory constructions of sexual assault or rape. In some part, then, both participate in the un-making of this chasm, a task which, both show, involves listening to and linking experiences, and changing what is common sense and "normal." Nevertheless, the task 
of un-making—or making sense of - this chasm may involve more than mapping ethical grey areas and fabricating conceptual tools that can be used to distinguish between varying degrees of sexual violation. To do so may first entail understanding sexual violence in a way that does not defer to or reproduce regulative ideals extracted from the law.

\subsection{One-in-Five}

Some might view the recourse to legalistic evaluations of Grace's narrative as fair game because of the public, targeted and explicit nature of her accusations. However, legalistic and antagonistic responses are neither infrequent nor limited to stories like Grace's. Instead, public discussions around sexual violence-whether on college campuses, in the workplace or in the context of relationships-are often subjected to legalistic interrogations-even in the absence of references to specific allegations or individuals. Legality is frequently invoked as a response to the full range of sexual violence narratives, whether they involve targeted accusations, anonymous stories or even references to aggregate rape statistics.

In 2014, President Obama launched an initiative to end what many viewed as a crisis of sexual assault on college campuses. In a speech to the White House Council on Women and Girls, the president lamented the frequency of campus-based sexual violence, citing the " 1 in 5 women on college campuses [who have] been sexually assaulted during their time there" (Obama 2014). Obama's reference to "1-in-5" - a statistic that had been, most recently, derived from research generated by the American Association of Universities-represents a way of empirically grounding a broader discussion about the effects of sexual violence and the responsibility of public officials to make college a safer place, especially for women (the predominant victims of sexual violence). ${ }^{6}$ Although it painted a grim picture of the risks of sexual violence, especially for college-age women, the statistic was in no way an aberration or an artifact of a single study. While there is significant disagreement over the methods and metrics used to evaluate the incidence of sexual assault-and therefore sizeable variation in the rates calculated by researchers-there are other studies that have derived similarly unsettling statistics (Malmsheimer 2014).

For instance, in 2000, the Bureau of Justice Statistics issued a report estimating the risks of rape that women face during an average five-year college career as "between one-fifth and one-quarter" (Fisher et al. 2000, p. 10). Scholarship based on research generated by Ms. Magazine references one-in-six women who had been the victim of completed or attempted rape during the previous year-and more than one-in-four who had been the victims of completed or attempted rape since the age of 14 (Warshaw 1988). These statistics were widely publicized on college campuses during the late 1990s during first-year orientations and dorm meetings, and inspired campuses to encourage women to carry "rape whistles" and laminated emergency cards. This most recent iteration of one-in-five seemed consistent with at least some of the better-known studies of campus-based assault.

However, despite its conformity to decades old studies, when President Obama referenced "1-in-5" to promote a "fundamental change in our culture-a shift in how we think about sexual violence", (Obama 2014) reporters and pundits flocked to the airwaves and the Internet to express their profound dismay as well as doubt. They were dismayed over the fact that politicians were both publicly referencing the statistic and using it to promote safety measures on campus. They doubted whether the statistic was even true. Reporters sidestepped the bigger story-the increased rates and risks of substance abuse, depression or suicidality that accompany sexual violence; the ongoing struggles that victims encounter when building and maintaining relationships; and the decreased capacities to have trust in others and have confidence in oneself-especially when sexual violence happens at the hands

6 This statistic has been reproduced in several studies commissioned more recently-including in surveys that sampled a broader cross-section of American colleges and universities. 
of an acquaintance or intimate partner. Instead, reporters of all partisan and ideological stripes focused on debunking " 1 -in-5".

The bulk of these criticisms made either direct or thinly veiled allusions to legalistic conceptions of rape or sexual assault - and focused especially on what critics perceived as a vast departure between the standards or definitions used in formal legal proceedings and researcher or respondent understandings of sexual violence. Their primary targets were the American Association of Universities Survey and a survey of all adult women generated by the Centers for Disease Control that had calculated a similar rate of rape among all women. These surveys, explained one reporter investigating the "one-in-five" statistic, employ a behavior-based rather than a criminal-justice approach to data collection and coding. A criminal-justice-or what we would refer to as a legalistic-approach asks respondents directly whether they have been raped or sexually assaulted (Kessler 2015). Surveys that utilize this kind of approach to questions and coding - such as the oft-cited Bureau of Justice Statistics survey (BJS) - typically reveal far lower rates of sexual assault than surveys or interviews that are centered on behaviors or experiences (Kessler 2015). Although the BJS survey had revealed a similarly high estimation of campus-based rape in 2000, its recent estimates calculated a far lower risk for college women. Researchers have long criticized the criminal-justice approach for failing to account for two serious drawbacks of the legalistic lens: that victims of sexual assault or rape may be reticent to recognize or acknowledge their experience with unwanted or nonconsensual sex as rape or sexual assault and that survey participants are either unaware of or will shy away from applying legal standards and conceptions to their own experiences (Kessler 2015).

Feminists argue that among the most enduring symptoms of sexual violence is the inability for victims to name their experience as violence or assault even when they feel violated and forced. This fact, after all, is what compelled consciousness-raising activists to push for spaces and strategies to help victims express their anger, sadness, confusion, and rage over having been stripped of their right to authorize the use of their own body-and to hold others responsible for their pain. Recognizing that the BJS survey likely replicated factors that lead to underreporting and, therefore, likely underestimated the incidence of sexual violence on campus, surveys such as the AAUS or the CDC survey deliberately employ a behavioral approach. These surveys avoid using legalistic concepts and instead ask participants to choose from a variety of plausible descriptions of sexual experiences or respond to a set of open-ended questions. Included in the questions are language and descriptors that allow participants to indicate the degree to which their sexual experiences were nonconsensual, forced, coerced or the result of incapacitation.

Once collected, the data are then analyzed and coded by researchers according to widely agreed upon standards (derived from legal settings) for what constitutes different forms of sexual violence. Not surprisingly, given what we know about how difficult it is for individuals to acknowledge or "correctly label" their own experiences of "sexual assault," surveys using the behavioral approach reveal higher rates of sexual violence. However, both the results-and the process itself-were treated with extreme skepticism shortly after Obama referenced the findings of behavior-based research. The bulk of the doubt leveled against " 1 -in-5" and the behavior-based surveys centered on the lack of legal concepts referenced in the survey. For instance, Glenn Kessler (2015) of the Washington Post took particular issue with this question in the survey:

Sometimes sex happens when a person is unable to consent to it or stop it from happening because they were drunk, high, drugged, or passed out from alcohol, drugs, or medications. This can include times when they voluntarily consumed alcohol or drugs or they were given drugs or alcohol without their knowledge or consent. Please remember that even if someone uses alcohol or drugs, what happens to them is not their fault. When you were drunk, high, drugged, or passed out and unable to consent, how many people have ever....

Kessler spends considerable time assessing the degree to which coding of these responses as rape have, mistakenly, included instances of consensual, yet inebriated, sexual encounters. Positive responses to this question account for approximately $50 \%$ of the rapes calculated by analysts. Kessler 
references the fact that $\mathrm{CDC}$ officials had developed specific protocols when interviewing each survey participant-making sure that respondents understood the question to include only nonconsensual instances of "under the influence" or "incapacitated" sexual encounters, rather than consensual acts. However, he dismisses-without any evidence, save the magnitude of the results—-the utility and legitimacy of the question and its inclusion as an indication of sexual violence.

Christina Hoff Sommers, of the American Enterprise Institute (AEI), similarly cast doubt on the inclusion of alcohol or drug-induced incapacitation as a context for nonconsensual sex. She asks:

If a woman was unconscious or incapacitated then every civilized person would call it rape.

But what about sex while inebriated? I mean, few people would say that intoxicated sex alone constitutes rape, indeed a nontrivial percentage of all customary, sexual intimacy-including marital sex-probably falls under that definition. (Schow 2014)

Supporting the legalistic-survey approach over behavior-based strategies, she states, plainly, "No one interviewed was asked if they'd been raped or sexually assaulted" (Schow 2014). Note Sommers' inclusion of marital sex as seemingly beyond the reach of rape and sexual assault-a nod to outdated and deeply limiting conceptions of the marital context as being exempted from instances of sexual violence.

After striking down the notion that alcohol-induced incapacitation or nonconsent is a form of sexual assault, Kessler moves on to what he regards as "interesting oddities" in the CDC survey. Here, he notes, "something called 'sexual coercion'"' (Kessler 2015)—casting doubt on the long-held belief that victimization in the context of sexual violence includes not only physical force but also threat, pressure and other nonphysical forms of duress. The second "oddity," according to Kessler, is the "made to penetrate" question-a recent addition to behavior-based surveys. These questions are meant to respond to another deficiency in criminal-justice surveys: the failure to capture male victims of sexual violence. Statistics on rape and sexual assault have traditionally focused on women as the primary victims of sexual violence-and men as the perpetrators (Struckman-Johnson and Struckman-Johnson 1994). One explanation for this could be that, empirically, women are more likely to be raped and men more likely to perpetrate rape. Another explanation, however, stems from the criminal-justice model of forcing victims to apply legalistic labels to their sexual victimization (Stemple and Meyer 2014). If men have traditionally been counted out of the statistics on sexual assault, they are far less likely to see concepts such as "rape" or "sexual assault" as applicable or relevant to their own experiences of sexual violence (Mezey and King 1987). This is true even if the characteristics of the acts themselves-forced sex-provide clear-cut instances of sexual violence. Alluding to this question as an attempt to capture incidents "allegedly involv[ing] women forcing men to engage in sex," Kessler seems to cast doubt on the possibility that men can experience sexual violence as victims as well as perpetrators (Kessler 2015). In fact, the author offers little more than an allusion to tradition as a reason for not addressing male sexual victimization: men have never been considered the victims of sexual violence, and, therefore, they never will. Of course, this is exactly the kind of intransigence in our understanding of sexual violence that the question is trying to empirically dispel.

Generally, critics and skeptics of "1-in-5" and its accompanying narratives, hold up the criminal-justice or "legalistic" approach to data collection as legitimate and behavior-based surveys as the work of charlatans. In her article, tellingly titled "Obama and the fiction of 'Rape Culture,"' Hill reporter Wendy McElroy (2014) refers to the BJS approach as "reasonable" and its findings (6.1 out of 1000 female college students) as the "actual rate of sexual assault" on campus. In so doing, she casts aside behavior-based researchers as either imposters or agents of "rape culture zealots" (McElroy 2014). David French, a reporter for the National Review, describes "1-in-5" as having produced "hysteria" on college campuses by promoting a "fake crisis" of sexual violence (French 2017). US News reporter Caroline Kitchens (2013) portrays "1-in-5" as an "alarming statistic" responsible for promoting a "movement built on a foundation of dubious statistics and a distorted view of masculinity." As part of a panel organized by the Independent Women's Counsel, ironically called "An Honest Conversation About 'Rape Culture' and Sexual Violence," AEI's Christina Hoff Sommers likens "1-in-5," and the 
momentum it had produced, to the "day-care sexual abuse hysteria of the 1980s." "It appears to me," she argues, "we are in the throes of one of those panics where paranoia, censorship, false accusations flourish" (Malmsheimer 2014).

Indeed, concerns about false accusations is what animates many of these criticisms. However, these criticisms are misplaced. Unlike the Ansari article, which provoked equally high levels of skepticism, the one-in-five statistic is an aggregate and anonymous account of individuals who have experienced versions of sexual violence. The statistic in no way provides detailed information about specific instances of sexual violence. Neither does it invoke legal allegations against a specific person. However, despite the anonymity and generality of this statistic, legalistic anxieties of due process reign supreme in these articles. Of course, the connection between "1-in-5" and due process is not wholly arbitrary. Spurred, in part, by the frequency of sexual violence on campus, President Obama issued a directive to college campuses-as part of his guidance on Title IX implementation-to reduce the evidentiary standards used by campus-based sexual assault tribunals (referred to by some as "kangaroo courts" (Pope 2012)). Prior to the institution of this new standard, Title IX permitted campus-based adjudicatory proceedings to evaluate allegations of sexual assault using a "clear and convincing" standard for evaluating the likelihood of guilt. Schools that adopted this standard asked those in a position to judge these proceedings to reach a conclusion of guilt only if the evidence indicated at least a 75 percent likelihood of guilt. As part of his multi-pronged initiative to mete out sexual violence on campus, President Obama instructed universities to use a "preponderance of evidence" standard. This standard, which had been used by multiple universities prior to the issuing of the guidance, permits adjudicators to determine guilt if they feel that most of the evidence points in that direction, and it is the standard used in most civil cases (Baker 2015).

Some critics of " 1 -in- 5 " encased their concerns about the statistic within a broader attack on Obama's new evidentiary guidelines. Their concern centered on the now increasingly threatened due-process rights of those accused of sexual assault. Within their methodological assessments of "1-in-5" and the behavior-based research that supported this statistic, critics cited with certainty that campuses would be "treacherous places for falsely accused men" (Kitchens 2013). In support of these fears, critics offered no statistical evidence-nothing to combat, for instance, the single-digit rates of reporting among victims of sexual assault or the extremely low likelihood of success among the small number who do report their experiences. Instead, reporters rested their claims on specific failures of due process-cases where an individual had been found innocent, or where a tribunal later found the existing evidence to be insufficiently compelling after a guilty verdict had initially been reached.

Of course, these due-process considerations are important. No system of adjudication should set aside the due-process considerations of those accused of campus-based violations. There may be good reason to worry about the reduced standard of evidence required on Obama's Title IX interpretations (later revised by President Trump). However, as in the Ansari example referenced above, there are ways to make these due-process arguments without attacking the veracity, credibility and validity of the men and women who responded to these surveys-without downgrading or casting doubt on their experiences. Unfortunately, however, the upgrading of due-process rights for alleged perpetrators at the expense of those who just want to talk about sexual violence is a tradition-and a clear consequence - of using a legal lens to respond to and digest extra-legal discussions about sexual violence. It is one thing to highlight the due-process rights of those accused of sexual assault, and to weigh them against the rights of victims engaging in formal legal action. This standard is at the core of the rule of law. It is entirely another to challenge the capacity for individuals to name, identify and acknowledge their own experience with sexual violence in anonymized settings in service of due-process rights that are not the least bit threatened.

\section{Conclusions}

Consciousness-raising helps survivors see forced sex as something different from, and anathema to, intimacy. It helps those who have experienced sexual violence to understand that, while 
masquerading as sex, coopting its gestures and locations, sexual violence subverts and attempts to annihilate the benefits of sex-intimacy, connectivity, agency and pleasure. However, as highlighted, there are circumstances in which the imposition of legality on consciousness-raising discourse may distort and disrupt the possibility of survivors seeking comfort, solace and support through dialogue. In these circumstances, and whether intentional or not, legality in the context of consciousness-raising potentially operates in ways that are counterproductive, encouraging victims of sexual violence to stay silent and to second-guess their experiences, perceptions and reactions. Where legal doctrine marginalizes victims of sexual violence from using the law to mete out justice for their pain, the examples of legality presented above, we argue, show how legality can quarantine victims from others who may help them distinguish sex from violence and understand sexual violence itself as a form of force and battery made possible by certain forms of social arrangement. At its most extreme, legality is a troubling impediment, foreclosing opportunities for victims of sexual violence to share their experiences.

That legal precept, in some circumstances, becomes fused with everyday notions of sexual violence is unsurprising. As some scholars studying the juridification of everyday discourse like to point out, this phenomenon is not new. For example, Mary Ann Glendon (1991) opens Rights Talk with a familiar quotation from Alexis de Tocqueville's Democracy in America, writing, "Wherever he went, he found that lawyers' habits of mind, as well as their modes of discourse, 'infiltrate through society right down to the lowest ranks'" (p. 1). What Tocqueville describes are habits of mind and modes of discourse that are ubiquitous. However, it would be a mistake to construe legality as totalizing. The circulation of legal precept through the social imaginary-the operations of legality in everyday understandings-is neither necessary nor inevitable. Discursive logics, standards, norms, must be continuously reproduced, re-sedimented, and re-enforced. The "social imaginary" is not a monolith, with essential, immutable features. It is always becoming. It has no definite shape or form. It has no content that cannot be un-made and changed. In this vein, the story of \#MeToo and legality in everyday responses to sexual violence is as much about resistance, controversion, and thinking beyond or without respect for the strictures of law-patterns of thinking and ways being in the world that are unregulated by legality and its logics—as it about a retrenchment of legal understanding.

However, before legal discourse, models of legal reasoning and legal process are excised from everyday discussions of and responses to sexual violence, legality, its operations and its effects, must be drawn into focus and evaluated. Consciousness-raising discourse, in the form of \#MeToo or behavior-based surveys, has, in part, served this function. It has, in some instances, encouraged and enabled debate about the use of legally-enshrined binaries and categories in everyday assessments of sexual violence. By engendering critics, consciousness-raising often highlights the mismatch of legality with consciousness-raising-and perhaps more profoundly the mismatch of law with sexual violence.

However, questions remain. Coming to grips with the effects of legality within the context of sexual-violence-focused consciousness-raising efforts is not something that can be accomplished in a single essay. Further research is needed, whether to elucidate legality's positive payoffs, or to explore its capacity to atomize, individualize, silence, and constrain links to community. A potentially effective route for studying these effects is by comparing, for instance, the structure and features of discourse on sexual violence in the United States with the discursive structure and features that typify responses to sexual violence in regions with different legal standards, procedures or norms. Such a comparative study could put into relief the limits of or even invalidate our argument about legality, by showing how it is particular kinds of social, rather than legal, arrangements that are principally responsible for the kinds of debates discussed above. Further, a more precise accounting is needed to show how legality operates in the context of sexual violence. How does it create the confusion and ambiguity that characterizes "Grace's" experience-or the pushback against "1-in-5"? Why, and in what way, do individuals rely on statutory constructions of rape and sexual assault as benchmarks and standards for assessing discussions of sexual violence? What are the circumstances under which legality is deployed or invoked? To answer these questions, one must speak not only to sexual violence 
survivors but also to any individual who may be called upon to hear, respond to or address accounts of sexual violence.

Nevertheless, an assessment of \#MeToo and public media responses to the one-in-five statistic represent a starting point. Helpfully, addressing the ways in which legal discourse has the potential to shape or color everyday responses to sexual violence becomes easier within the context of a moment when these constraints are being made the object of routine, focused scrutiny. Consciousness-raising approaches like \#MeToo may not be a watershed. However, the persistence and resilience of consciousness-raising as a productive and empowering counterpoint to law's technical and legalistic constraints has trained attention on these constraints as well as persistent deeply-rooted patterns of oppression, whose ubiquity forces discussion. One hopes this discussion, whatever turn it takes, will furnish resources and forms of discourse that make grappling with the enduring problem of sexual violence possible.

Author Contributions: The article was conceived, drafted, and revised by A.G. and R.H.

Conflicts of Interest: The authors declare no conflict of interest.

\section{References}

Adler, Zsuzsanna. 1987. Rape on Trial. London: Macmillan Press.

Baker, Katharine. 2015. Why Rape Should Not (Always) Be a Crime. Minnesota Law Review 100: 221-78.

Bumiller, Kristin. 1987. Rape as a legal symbol: An essay on sexual violence and racism. University of Miami Law Review 42: 75-91.

Cahill, Ann J. 2016. Unjust Sex vs. Rape. Hypatia 31: 747-61. [CrossRef]

Campbell, Rebecca. 2005. What Really Happened? A Validation Study of Rape Survivors' Help-Seeking Experiences with the Legal and Medical Systems. Violence and Victims 20: 55-68. [CrossRef] [PubMed]

Campbell, Alexia Fernández. 2018. The Legal Difference Between Sexual Misconduct, Assault, and Harassment, Explained. Vox. Available online: https://www.vox.com/policy-and-politics/2018/1/26/16901998/ definitions-sexual-misconduct-harassment-assault (accessed on 12 February 2018).

Caringella, Susan. 2009. Addressing Rape Reform in Law and Practice. New York: Columbia University Press.

Cuklanz, Lisa M. 1996. Rape on Trial. Philadelphia: University of Pennsylvania Press.

Dalmia, Shikha. 2017. \#MeToo is Turning into a Witch-Hunt. Reason. Available online: http://reason.com/ archives/2017/12/27/metoo-is-turning-into-a-witch-hunt (accessed on 10 February 2018).

Davis, Kathy, and Dubravka Zarkov. 2018. Ambiguities and dilemmas around \#MeToo: \#ForHowLong and \#WhereTo? European Journal of Women's Studies 25: 3-9.

Dreyfuss, Ben. 2015. Donald Trump's Layer: Marital Rape Cannot Be Rape. Mother Jones. Available online: https:/ / www.motherjones.com/politics /2015/07/donald-trumps-lawyer-marital-rape-cannot-be-rape/ (accessed on 5 August 2016).

Du Mont, Janice, Karen Lee Miller, and Terri Myhr. 2003. The Role of 'Real Rape' and 'Real Victim' Stereotypes in the Police Reporting Practices of Sexually Assaulted Women. Violence against Women 9: 466-86. [CrossRef]

Edwards, Stassa. 2018. It's Time to Map the Wilderness of Bad Sex. Jezebel. Available online: https://jezebel.com/ its-time-to-map-the-wilderness-of-bad-sex-1822171954 (accessed on 10 February 2018).

Engel, David M. 1995. Law in the domains of everyday life: The construction of community and difference. In Law in Everyday Life. Edited by Austin Sarat and Thomas R. Kearns. Ann Arbor: University of Michigan Press.

Escobedo Shepherd, Julianne. 2018. Babe, What Are You Doing? Jezebel. Available online: https://jezebel.com/ babe-what-are-you-doing-1822114753 (accessed on 10 February 2018).

Estrich, Susan. 1987. Real Rape. Cambridge: Harvard University Press.

Estrich, Susan. 2008. Rape. In Women and the Law, 4th ed. Edited by Libby Adler, Lisa Crooms, Judith Greenberg, Martha Minow and Dorothy Roberts. New York: Foundation Press/Thompson-West, pp. 199-210.

Ewick, Patricia, and Susan S. Silbey. 1998. The Common Place of Law: Stories from Everyday Life. Chicago: University of Chicago Press.

Fargo, Paula. 2017. \#Metoo Campaign Perpetuates Female Victimhood. The Baltimore Sun. Available online: http:/ / www.baltimoresun.com/news/opinion/oped/bs-ed-op-1207-metoo-victimhood-20171205story.html (accessed on 11 February 2018). 
Fisher, Bonnie, Francis Cullen, and Michael Turner. 2000. The Sexual Victimization of College Women. National Institute of Justice/Bureau of Justice Statistics. Available online: https://www.ncjrs.gov/pdffiles1/nij/ 182369.pdf (accessed on 21 May 2018).

Flanagan, Caitlin. 2017. To Hell with the Witch-Hunt Debate. The Atlantic. Available online: https://www. theatlantic.com/entertainment/archive/2017/11/to-hell-with-the-witch-hunt-debate/546713/ (accessed on 12 February 2018).

Flanagan, Caitlin. 2018. The Humiliation of Aziz Ansari. The Atlantic. Available online: https://www.theatlantic. com/entertainment/archive/2018/01/the-humiliation-of-aziz-ansari/550541/ (accessed on 12 February 2018).

French, David. 2017. Campus Rape Hysteria: Trump's Education Department Takes on the Campus-Rape Lie. National Review. Available online: https:/ /www.nationalreview.com/2017/07/campus-rape-hysteriatrumps-education-department-can-restore-due-process / (accessed on 6 September 2017).

Fricker, Amanda. 2007. Epistemic Injustice: Power and the Ethics of Knowing. Oxford: Oxford University Press.

Friedman, Lawrence. 2002. American Law in the 20th Century. New Haven: Yale University Press.

Frohmann, Lisa, and Elizabeth Mertz. 1994. Legal Reform and Social Construction: Violence, Gender, and the Law. Law E Social Inquiry 19: 829-51.

Gash, Alison, and Judith Raiskin. 2016. Parenting without Protection: How Legal Status Ambiguity Affects Lesbian and Gay Parenthood. Law \& Social Inquiry 43: 82-118.

Geesen, Masha. 2017. When Does a Watershed Become a Sex Panic? The New Yorker. Available online: https: //www.newyorker.com/news/our-columnists/when-does-a-watershed-become-a-sex-panic (accessed on 11 February 2018).

Gilbert, Sophie. 2017. The Movement of \#MeToo. The Atlantic. Available online: https:/ /www.theatlantic.com/ entertainment/archive/2017/10/the-movement-of-metoo/542979/ (accessed on 10 February 2018).

Glendon, Mary Ann. 1991. Rights Talk: The Impoverishment of Political Discourse. New York: The Free Press.

Hill, Zahara. 2017. A Black Woman Created the 'MeToo' Campaign against Sexual Assault Ten Years Ago. Ebony. Available online: http:/ / www.ebony.com/news-views/black-woman-me-too-movement-tarana-burkealyssa-milano (accessed on 21 May 2018).

Hogan, Holly. 2013. Law Reform Efforts: Rape and Sexual Assault in United States of America. International Models Project on Women's Rights. Available online: http:/ /www.impowr.org/content/law-reform-effortsrape-and-sexual-assault-united-states-america (accessed on 21 May 2018).

Kelland, Lindsay. 2016. A Call to Arms: The Centrality of Feminist Consciousness-Raising Speak-Outs to the Recovery of Rape Survivors. Hypatia 31: 730-45. [CrossRef]

Kessler, Glenn. 2015. Obama's Claim That One in Five American Women Has Been the Victim of Rape. The Washington Post. Available online: https://www.washingtonpost.com/news/fact-checker/wp/2015/ 02/12/obamas-claim-that-one-in-five-american-women-have-been-raped $/$ ?noredirect=on\&utm_term= .cec79962d4bf (accessed on 21 May 2018).

Kitchens, Caroline. 2013. The Rape Epidemic Doesn't Actually Exist. U.S. News and World Report. Available online: https://www.usnews.com/opinion/blogs/economic-intelligence/2013/10/24/statistics-dont-backup-claims-about-rape-culture (accessed on 21 May 2018).

Lambert, Lisa. 2018. MeToo Effect: Calls Flood U.S. Sexual Assault Hotlines. Reuters. Available online: https://www.reuters.com/article/us-usa-harassment-helplines/metoo-effect-calls-flood-u-ssexual-assault-hotlines-idUSKBN1F6194 (accessed on 21 May 2018).

Levit, Nancy, and Robert Verchick. 2016. Feminist Legal Theory, 2nd ed. New York: New York University Press.

MacKinnon, Catharine A. 1995. Reflections on Law in the Everyday Life of Women. In Law in Everyday Life. Edited by Austin Sarat and Thomas R. Kearns. Ann Arbor: University of Michigan Press, p. 199.

MacKinnon, Catharine A. 2005. Women's Lives, Men's Laws. Boston: Harvard University Press.

Malmsheimer, Taylor. 2014. Conservatives are Obsessed with Debunking the 1 in 5 Rape Statistic. They're Wrong Too. The New Republic. Available online: https:/ / newrepublic.com/article/118430/independent-womensforum-challenges-one-five-statistic (accessed on 21 May 2018).

Maurer, Sara. 2018. The \#MeToo Movement Isn't about Women's Frailty. It's About Women's Labor. The Chronicle of Higher Education. Available online: https:/ / www.chronicle.com/article/The-MeToo-Movement-Isn-t/ 242179 (accessed on 11 February 2018).

McElroy, Wendy. 2014. Obama and the Fiction of 'Rape Culture'. The Hill. Available online: http:/ / thehill.com/ blogs/pundits-blog/education/228027-obama-and-the-fiction-of-rape-culture (accessed on 21 May 2018). 
Mezey, Gillian, and Michael King. 1987. Male Victims of Sexual Assault. Medicine, Science and the Law 27: 122-24. [CrossRef] [PubMed]

Noveck, Jocelyn. 2017. In Sex Assault Laws, Definition of Consent Varies Widely. Associated Press. Available online: https: / www.apnews.com/ec7bca54931544f7b71651406566206b /In-sex-assault-laws,-definitionof-consent-varies-widely (accessed on 10 February 2018).

Obama, Barack. 2014. Remarks by the President and Vice President at an Event for the Council on Women and Girls. Available online: https://obamawhitehouse.archives.gov/the-press-office/2014/01/22/remarkspresident-and-vice-president-event-council-women-and-girls (accessed on 21 May 2018).

Panahi, Rita. 2017. Meet the Women Worries About \#MeToo. Spiked. Available online: http://www.spikedonline.com/newsite/article/meet-the-women-worried-about-metoo/20639\#.WonSFYJG0Wp (accessed on 11 February 2018).

Pope, Justin. 2012. On Campus, Debate over Civil Rights and Rape. U.S. News E World Report. Available online: https:/ /www.usnews.com/news/us/articles/2012/04/21/on-campus-debate-over-civil-rightsand-rape?s_cid=related-links:TOP\&page=5 (accessed on 21 May 2018).

Quilter, Julia. 2015. From Raptus to Rape: A History of the Requirements of Resistance and Injury. Law E History 2: 89-113.

Rothschild, Nathalie. 2017. Meet the Women Worried About \#MeToo. Spiked. Available online: http:/ / www.spiked-online.com/newsite/article/meet-the-women-worried-about-metoo/20639\# .WonSFYJG0Wp (accessed on 11 February 2018).

Schow, Ashe. 2014. No, 1 in 5 Women Have Not been Raped on College Campuses. Washington Examiner. Available online: https://www.washingtonexaminer.com/no-1-in-5-women-have-not-been-raped-oncollege-campuses (accessed on 21 May 2018).

Schulhofer, Stephen. 2017. Reforming the Law of Rape. Law E Inequality: A Journal of Theory and Practice 35: 335-52.

Seltzer, Sara. 2017. \#MeToo Has Debunked the 'Lean In' Philosophy. The Nation. Available online: https:/ / www. thenation.com/article/metoo-has-debunked-the-lean-in-philosophy/ (accessed on 11 February 2018).

Shane, Charlotte. 2018. We Harpies Want More. Splinter. Available online: https://splinternews.com/we-harpieswant-more-1822022182 (accessed on 11 February 2018).

Stemple, Lara, and Ilan Meyer. 2014. The Sexual Victimization of Men in America: New Data Challenge Old Assumptions. American Journal of Public Health 104: 19-26. [CrossRef] [PubMed]

Struckman-Johnson, Cindy, and David Struckman-Johnson. 1994. Men Pressured and Forced into Sexual Experience. Archives of Sexual Behavior 23: 93-114. [CrossRef] [PubMed]

Tolentino, Jia. 2018. The Rising Pressure of the \#MeToo Backlash. The New Yorker. Available online: https: / / www.newyorker.com/culture/culture-desk/the-rising-pressure-of-the-metoo-backlash (accessed on 11 February 2018).

Tracy, Carol, Terry Fromson, Jennifer Long, and Charlene Whitman. 2013. Rape and Sexual Assault in the Legal System. Women's Law Project/ÆQUITAS. Available online: http://jpp.whs.mil/Public/docs/04-Meetings / sub-20150507/03_Rape_SexAsslt_LegalSystem_WLP_AEQuitas_20120605.pdf (accessed on 10 February 2018).

Warshaw, Robin. 1988. I Never Called it Rape. New York: Harper Perennial.

Way, Katie. 2018. I Went on a Date with Aziz Ansari. It Turned into the Worst Night of My Life. Babe. Available online: https:/ / babe.net/2018/01/13/aziz-ansari-28355 (accessed on 12 February 2018).

Weiss, Bari. 2017. The Limits of ‘Believe All Women. The New York Times. Available online: https:/ / www.nytimes. com/2017/11/28/opinion/metoo-sexual-harassment-believe-women.html (accessed on 12 February 2018).

Weiss, Bari. 2018. Aziz Ansari is Guilty. Of Not Being a Mind Reader. The New York Times. Available online: https:/ /www.nytimes.com/2018/01/15/opinion/aziz-ansari-babe-sexual-harassment.html (accessed on 12 February 2018).

Yoffe, Emily. 2017. Why the \#MeToo Movement Should be Ready for a Backlash. Politico. Available online: https: / / www.politico.com/magazine/story /2017/12/10/yoffe-sexual-harassment-college-franken216057 (accessed on 11 February 2018).

(C) 2018 by the authors. Licensee MDPI, Basel, Switzerland. This article is an open access article distributed under the terms and conditions of the Creative Commons Attribution (CC BY) license (http:/ / creativecommons.org/licenses/by/4.0/). 